\title{
Local Structure and Composition Change at Surface of Lithium-ion Conducting Solid Electrolyte
}

Hirotoshi Yamada*, Koshin Takemoto

Graduate School of Engineering, Nagasaki University

1-14, Bunkyo-machi, Nagasaki 8528521, Japan

*Corresponding author:

1-14, Bunkyo-machi, Nagasaki 8528521, Japan

e-mail: h-yama@nagasaki-u.ac.jp

TEL/FAX: +81-95-819-2861 


\begin{abstract}
In this study, three different surface-sensitive techniques, grazing incidence X-ray diffraction (GIXD), attenuated total reflectance Fourier transform infrared (ATR-FTIR), and X-ray photoelectron spectroscopy (XPS), were employed to analyze the local structure and composition around the surface region of a lithium ion conducting solid electrolyte sheet. It was revealed that the local structure and composition changed depending on depth from the top surface of the sheet. At the very surface, there was a layer with expanded lattice and high Li composition. And with increasing the depth from the surface, lattice shrank sharply, and then expanded again gradually. The change in the lattice seemed to be accompanied by $\mathrm{Li}$ and $\mathrm{Al}$ composition. It was supposed that the change in the Li composition and structure is induced by combination of chemical reaction, segregation, and defects distribution.
\end{abstract}

Keywords: Solid electrolyte; Surface structure; Grazing incidence X-ray diffraction; Attenuated total reflectance Fourier transform infrared; X-ray photoelectron spectroscopy. 


\section{Introduction}

Recently, lithium ion conducting solid electrolytes attract many interests because of their potential application to all-solid-state batteries (ASSBs), which are supposed to be one of candidates of next-generation energy storage devices with high safety and reliability [1-3]. Relatively poorer ionic conductivity has been a drawback of solid electrolytes in comparison to conventional electrolyte solutions with organic solvents. However, a door has been opened since novel solid electrolytes that are comparable or surpass liquid electrolytes in ionic conductivity were developed by pioneering works in the last few decades[2,4-8]. As a result of many efforts to increase lithium ion conductivity of bulk solid electrolytes, interfacial resistance especially between solid electrolytes and active materials appears as a next critical issue. The cause of interfacial resistance can be classified to two factors: extrinsic factors and intrinsic factors. One of critical extrinsic factors is interfacial resistance arising from point-contact interface between solid electrolytes and active materials, which may be suppressed by employing solid electrolytes with plasticity [9,10]and/or low melting point[11]. On the other hand, intrinsic factors are unclear. Three plausible mechanisms have been reported as an origin of the intrinsic interfacial resistance: formation of interphases $[9,12]$, depletion of mobile ions due to space charge layer (SCL) $[1,13,14]$, and distortion of crystal lattice 
because of lattice mismatch[12]. According to theSCL model, theSCL is about twice ofDebye length in thickness and is calculated to be less than $1 \mathrm{~nm}$ for high ionic conductors. However, a few studies indicate that much thicker SCL. Iriyama's group investigated the potential profile at the interface between a cathode and a solid electrolyte of an ASSB by electron beam holography, and revealed that potential gradient in the solid electrolyte ranges about $1 \mu \mathrm{m}$ in thickness from the interface[15]. We have so far studied the local structure at the interfacial region by fabricating nano-composites of active materials and solid electrolytes, and confirmed that the interfacial region with distorted lattice ranges for at least $20-50 \mathrm{~nm}$ in thickness[13,14]. To explain these discrepancies in the thickness of the SCL, we proposed the defect-pair model: interstitial lithium ions (denoted as $\mathrm{Li}_{i}{ }^{*}$ by Kröger-Vink notation) that are positive defects in a crystal lattice are bound to substituting ions (e.g. $\mathrm{Al}_{\mathrm{Ti}}{ }^{\prime}$ for LATP) in high ionic conductors that are negative defects. Although more researches with variety of experimental analysis are required for further comprehension of the interfacial phenomena, difficulty in the analysis of solid/solid interface limits experimental tools.

It is known that surface of solid electrolytes is also related to interfacial resistance. Kliewer proposed cation depletion at surface of ionic crystals when free energy of defect formation is lower for cation than for anion [16]. In addition, we observed that 
ball-milling of a poor ionic conductor $\left(\mathrm{Li}_{2} \mathrm{SiO}_{3}, \mathrm{LSO}\right)$ resulted in increase in ionic conductivity without change in activation energy $[13,17]$. This is interesting because size reduction of solid electrolyte particles generally increases grain boundary resistance, which is generally observed for high ionic conductor [14]. The enhanced ionic conductivity in the nano-LSO may be explained by three plausible mechanisms. One is related to packing of particles. The ball-milling causes not only reduce particle sizes, but also sharpen particle size distribution and particle shape becomes more spherical. The morphology change facilitates dense packing of particles and better contact among particles to improve the grain boundary resistance. Second mechanism is the formation of surface layer, i.e., change in phases, crystalline structure and/or distribution of ions (defects). The last is change in ion distribution, in other words, space charge layer (SCL) effect. With SCL model, conductivity enhancement in nano-LSO can be explained by type of charge carrier: Li vacancy $\left(V_{\mathrm{Li}}{ }^{\prime}\right)$ for LSO and interstitial $\mathrm{Li}^{+}\left(\mathrm{Li}_{i}{ }^{\circ}\right)$ for other high ionic conductors. The decreased $\mathrm{Li}^{+}$concentration at the surface means accumulation of carrier for LSO and depletion for the latter[17].

In this paper, local structure of surface of a solid electrolyte is focused on and investigated using various surface-sensitive analyses: grazing incidence X-ray diffraction (GIXD), attenuated total reflectance Fourier transform infrared (ATR-FTIR), 
and X-ray photoelectron spectroscopy (XPS).

\section{Experimental}

Mirror polished solid electrolyte sheets $(25.4 \mathrm{~mm} \times 25.4 \mathrm{~mm} \times 0.15 \mathrm{~mm}$,LICGC,

Oharainc.) were used for analyzing their surface. This solid electrolyte is a glass-ceramic of NASICON-type one in the $\mathrm{Li}_{2} \mathrm{O}-\mathrm{Al}_{2} \mathrm{O}_{3}-\mathrm{TiO}_{2}-\mathrm{GeO}_{2}-\mathrm{SiO}_{2}-\mathrm{P}_{2} \mathrm{O}_{5}$ system.According to the supplier, LICGC consists of $\mathrm{Li}_{1+x}\left(\mathrm{Al}_{x} \mathrm{Ge}_{y} \mathrm{Ti}_{2-x-y}\right)\left(\mathrm{PO}_{4}\right)_{3}$ as a main crystalline phase, and $\mathrm{Li}_{1+x+3 z} \mathrm{Al}_{x}(\mathrm{Ge}, \mathrm{Ti})_{2-x}\left(\mathrm{Si}_{z} \mathrm{PO}_{4}\right)_{3}$ and $\mathrm{AlPO}_{4}$ as subphases. Root-mean-square roughness of the sheets were $5.1 \mathrm{~nm}$ obtained by a scanning probe microscope (SPM-9600, Shimadzu Corp., see Supplementary Information S1). As shown in Figure S1, the roughness of the sheet is mainly due to holes $(10-20 \mathrm{~nm}$ in depth) on the surface of the LICGC, which is possibly formed by dropout of grains on the surface of LICGC on the polishing process. GIXD was conducted with asymmetric mode (or Seeman-Bohlin arrangement), which are explained in Supplementary Information, S2. GIXD profiles of LICGC were recorded on a SmartLab equipped with a rotating anti-cathode made of a $\mathrm{Cu}$ target $(45 \mathrm{kV}, 200 \mathrm{~mA}$,Rigaku Corp.). Soller slits for the incident and the diffracted beams were both 5 deg. and a parallel slit analyzer was0.5 deg. A graphite monochromator was used to suppress fluorescent X-ray. X-ray 
was irradiated to the LICGC sheets with various incidence anglesranging from 0.2 to $1.5 \mathrm{deg}$. There is another mode for GIXD, in-plane mode, in which the detector is scanned around a normal vector of a sample (Supplementary Information, S2). In this work, the asymmetric mode was employed because influence of refraction at the surface for the in-plane mode is complex and it was difficult to discuss the change in the lattice parameters.

ATR-FTIR was carried out using an IR-Prestage21 (Shimadzu Corp.) with a single ATR attachment MIRacleA (Ge prism) for the wavenumber range from 700 to 4000 $\mathrm{cm}^{-1}$.Penetration depth, $D_{\mathrm{p}}$, of infrared beam in an object is given by the following equation:

$D_{\mathrm{p}}=\frac{\lambda}{2 \pi n_{\mathrm{c}}}\left[\sin ^{2} \phi-\left(n_{\mathrm{s}} / n_{\mathrm{c}}\right)^{2}\right]^{-\frac{1}{2}}$

where $\lambda, n_{\mathrm{c}}, n_{\mathrm{s}}$ and $\phi$ are wavelength of infrared, a refractive index of a prism $\left(\mathrm{Ge}, n_{\mathrm{c}}=\right.$ 4.0 at $\lambda=1,000 \mathrm{~cm}^{-1}$ ), a refractive index of an object, and an incident angle, respectively. By assuming $n_{\mathrm{S}}$ of LICGC to be 1.4 , which is similar to a value of typical oxide glass and ceramics, $D_{\mathrm{p}}$ is ca. $650 \mathrm{~nm}$. To obtain bulk information, FTIR spectra of LATP powder obtained by milling LICGC with an agate mortar were also recorded by a conventional $\mathrm{KBr}$ method.

XPS was carried out using an AXIS-ULTRA DLD (KratosAnalytical Ltd.) with a 
monochromatedAlK $\alpha$ (photon energy: $1.4867 \mathrm{keV}, 15 \mathrm{kV}, 10 \mathrm{~mA}$ ). The detecter of the photoelectrons was placed at $90^{\circ}$ (perpendicular to the surface of LICGC).Spectra were recorded for C1s, Li1s, A12p, Ti2p, Ge3p, Si2p, P2p, and O1s with a pass-energy of 40 eV. On measurements, a charge neutrizer was used to avoid charging of an object. For the surface spectrum, contaminant carbon $(285.0 \mathrm{eV})$ on the surface of LICGCwas used for calibration of binding energy. To investigate depth profiles of elements, surface of LICGC were etched with coroneneion $\left(\mathrm{C}_{24} \mathrm{H}_{12}{ }^{+}\right)$beam sputtering to minimize change in the concentration of mobile ions.According to Yamamoto, Ar ion beam, which is often used for depth profile analyses of metals and ceramics, causes change in the concentration especially for mobile ions, while $\mathrm{C}_{60}$ ion beam results in no change in ion distribution [18]. $\mathrm{C}_{24} \mathrm{H}_{12}{ }^{+}$beam used in this work exhibits similar etching ability to $\mathrm{C}_{60}{ }^{+}$beam $[19,20]$. The acceleration voltage and the beam monitor current of the coronene ion beam were $7.9 \mathrm{kV}$ and $2 \mathrm{nA}$, respectively. The ion beam injected with an incidence angle of 40 degree was scanned on the surface of the specimen for $2 \mathrm{~mm} \times 2$ $\mathrm{mm}$ in size. The etching rate was estimated from a result for a standard $\mathrm{SiO}_{2}$ filmon a $\mathrm{Si}$ substrate. Composition of elements was calculated by fitting each spectrum using pseudo-Voigt functions with a Shirley's background.

Bulk composition of LICGC was also analyzed by inductively coupled plasma 
optical emission spectrometry (ICP-OES) using an ULTIMA2 (HORIBA, Ltd.). For the analysis, LICGC was dissolved with hot sulfuric acidand hydrofluoric acid aqueous solution.

\section{Results}

\subsection{GIXD}

Figure 1showsasymmetric GIXD profiles of a LICGC recorded with various incidence angles, ranging from 0.2 to $1.5 \mathrm{deg}$. For the comparison, a profile by a conventional $2 \theta / \omega$ scan is also exhibited.Although no impurity phase was confirmed for surface region (lower incidence angle in Figure 1(a)), it is obvious that peak position of diffraction peaks depended on incident angles (Figure 1(b)). With increasing incidence angle, peaks shifted towards lower angles, meaning expansion of the crystalline lattice in the surface region. Unfortunately, it was impossible to precisely calculate lattice parameters of LICGC, because LICGC contains two similar crystalline phases of $\mathrm{Li}_{1+x} \mathrm{Al}_{x} \mathrm{Ge}_{y} \mathrm{Ti}_{2-x-y} \mathrm{P}_{3} \mathrm{O}_{12}$ and $\mathrm{Li}_{1+x+3 z} \mathrm{Al}_{x}(\mathrm{Ge}, \mathrm{Ti})_{2-x}\left(\mathrm{Si}_{z} \mathrm{PO}_{4}\right)_{3}$. In this work, instead, $d$-values of (113) plane obtained by fitting each peak with a single Gaussian distribution function were compared (Figure 2(a)). Interestingly, the $d$-value changed non-monotonically with increasing the attenuation length: the very surface region of 
LICGC is expanded, and $d$-value dropped sharply. Then, lattice expanded again after a minimum around an attenuation length of $40 \mathrm{~nm}$. Next, the $d$-value exceeded bulk value again. Such expansion didn't relax even at 1,500 $\mathrm{nm}$ in depth. Figure 2(b) compares the expansion ratio of the $d$-value for 2 lattice planes (113) and (024), which agreed well with each other. This agreement suggests the lattice expansion/shrinkage is isotropic.

\subsection{FT-IR}

To compensate GIXD, which is sensitive to crystalline phases, FT-IR was conducted to reveal the local structure in LICGC. Figure 3 exhibitsATR and transmissionFT-IR spectra ofLICGC. For the transmission spectrum to obtain the bulk information,LICGC was milled with an agate mortar and a pestle, and then the obtained powder $(1 \sim 10 \mu \mathrm{m}$ in particle size) was mixed with $\mathrm{KBr}$ powder to form a pellet.As shown in Figure 3(a), peaks attributed to hydroxyl group and chemisorbed $\mathrm{H}_{2} \mathrm{O}$ on surface of LICGC were stronger in the ATR spectrum than for the powder [21-23], which confirms that the ATR method is sensitive to surface, while the transmission spectrum gives bulk information. Especially, a characteristic absorption peak attributed to a mono-layer chemically adsorbed hydroxyl group was confirmed. Therefore, information of very thin layer can

be obtained by the ATR method. For the wavenumber below $1,300 \mathrm{~cm}^{-1}$, peaks related 
to LICGC structure were observed, all of which could be attributed to NASICON-type structureas summarized in Table $1[24,25]$.The ATR spectrum suggests that $\mathrm{LiOH}$ (or $\mathrm{LiOH} \cdot \mathrm{H}_{2} \mathrm{O}$ ) and $\mathrm{Li}_{2} \mathrm{CO}_{3}$ may exist on the surface of LICGC. In Figure 3(a), $\mathrm{H}_{2} \mathrm{O}$ $\left(1,400-1,800 \mathrm{~cm}^{-1}\right), \mathrm{CO}_{2}\left(\sim 2,300 \mathrm{~cm}^{-1}\right)$ and surface hydroxyl group $(3,500-4,000$ $\mathrm{cm}^{-1}$ )were confirmed. However, strong vibrations that are characteristic toLiOH (indicated by dark blue bars) or $\mathrm{Li}_{2} \mathrm{CO}_{3}$ (green bars) were not clearly observed even in enlarged spectra (Figure 3 (b-d)).

In Figure 3(b), several vibration modes related to $M \mathrm{O}_{6}$ octahedra $(M=\mathrm{Al}, \mathrm{Ti}, \mathrm{Ge})$ and $\mathrm{XO}_{4}$ tetrahedra $(X=\mathrm{Si}, \mathrm{P})$ were observed [26]. For regular octahedral, $v_{1}$ and $v_{3}$ vibration modes are not observed in infrared spectra, and the appearance of these peaks in Figure 3(b) results from distortion of $M \mathrm{O}_{6}$ octahedra. When peaks for $M \mathrm{O}_{6}$ octahedra $\left(v_{1}: 650-670 \mathrm{~cm}^{-1}, v_{3}: 580-615 \mathrm{~cm}^{-1}\right)$ were focused on, it is found that peaksappeared at higher wavenumber for surface region (ATR) compared with bulk (powder), which indicates difference of mass and/or oxidation state of central atoms for bulk and surface $[26]$.

For a wavenumber range from 1,000 to $1,300 \mathrm{~cm}^{-1}$, peaks are ascribed to $\mathrm{PO}_{4}$ tetrahedra (Figure 3(c)). From the number of each vibration mode of $\mathrm{PO}_{4}$ tetrahedra, $\mathrm{PO}_{4}$ is supposed to exhibit $\mathrm{C}_{2 v}$ symmetry[26,27]. However, position of some peaks of 
$\mathrm{PO}_{4}$ vibration didn't agree with each other: $v_{1}$ for bulk (transmission) and surface (ATR)

were observed at $950 \mathrm{~cm}^{-1}$ and $978 \mathrm{~cm}^{-1}$, respectively. In addition, one of $v_{3}\left(1,028 \mathrm{~cm}^{-1}\right.$ for bulk). Thisdifference indicates change in the local bond lengths. In the case of olivine-type $\mathrm{LiFePO}_{4}$ and $\mathrm{FePO}_{4}$, which exhibit the same symmetry (Pnma) and different lattice parameters (i.e. different bond lengths), $v_{2}$ shifts to higher and $v_{1}$ shifts lower in wavenumber [28]. The change in the bond length is consistent with the results of GIXD.

\subsection{XPS}

The local distortion (change in the bond distance) was indicated by GIXD and FT-IR as shown above. In this section, depth profiles of composition are analyzed using XPS. Figure 4 demonstrates spectra showingP2p, Ge3p and A12p (Figure 4(a)), and A12p, Ti3s and Li1s (Figure 4(b)). Other spectra are shown in Figure S5 in Supplementary Information. Spectra were recorded before and after sputtered with coroneneion beam.

Figure 5 shows depth profiles of elements except for carbon, in which relative atomic ratio of each element to phosphorus are plotted. In addition, relative atomic ratio of bulk obtained by ICP-OESare shown in Figure 5. The composition of Ti/P, Ge/P and Si/P was almost independent of depth except for the region for ca. $10 \mathrm{~nm}$ from the surface, which 
is due to the thin surface layers such as $\mathrm{Li}_{2} \mathrm{CO}_{3}$ and/or $\mathrm{LiOH}$, and to a mechanically induced dropout of some grains suggested by SPM(see Figure S1). It is surprising that the surface region of LICGC exhibits different composition from bulk (ICP-OES). And $\mathrm{Li} / \mathrm{P}$ and $\mathrm{Al} / \mathrm{P}$ exhibited drastic change for more than $100 \mathrm{~nm}$ in depth. While Li/P seems to converge toward bulk ( $\left.\mathrm{Li}_{\mathrm{ICP}}\right), \mathrm{Al} / \mathrm{P}$ increased far from bulk composition.

\section{Discussion}

All of three different techniques to analyze the surface region of the solid electrolyte sheets indicated that surface region are different from bulk in local structure as well as composition. It seems that composition change (Figure 5) is correlated to lattice expansion/shrink (Figure 2). For the surface region upto ca. $50 \mathrm{~nm}$ in depth, lattice expands and $\mathrm{Li}$ is contained more than bulk. On the other hand, in the region deeper than $50 \mathrm{~nm}$, lattice shrinks and $\mathrm{Li}$ is reduced while $\mathrm{Al}$ increases.It is known that surface of materials is different from their internal structure because of different environment. There may be several possible mechanisms to explain the observed phenomena:(i) chemical reactions and/or mechanicalchange at the surface, (ii)gradient composition at the surface and (iii) defects distribution.

On the possibility of the mechanically/chemically induced change, Yamamoto et al. 
reported that the surface treatment such as polishing of soda-lime-glass resulted in depletion of sodium ions in the region adjacent to the surface[29, 30]. It is supposed that chemical reactions like ion exchange occurred on polishing the glass surface, which may also happen on the polished LICGC sheet. It is reported that LICGC exhibits ion exchange between $\mathrm{Li}^{+}$and proton in acidic solution [31]. However, ion exchange would cause depletion of lithium ions, which is against the experimental data. Therefore, it is supposed that the polishing and subsequent ion exchange is not the direct cause of the surface expansion.

When the surface of LICGC reacted with air and/or water, Li-rich phases consisting of $\mathrm{LiOH}$ and/or $\mathrm{Li}_{2} \mathrm{CO}_{3}$ may be formed. From ATR-FTIR (Figure 3), there seems trace of $\mathrm{LiOHand} /$ or $\mathrm{Li}_{2} \mathrm{CO}_{3}$, i.e. $\mathrm{LiOH} \cdot \mathrm{H}_{2} \mathrm{O}: 3,570 \mathrm{~cm}^{-1}$ and $\mathrm{LiOH}: 3,676$ $\mathrm{cm}^{-1}[32], \mathrm{Li}_{2} \mathrm{CO}_{3}: 1,440$ and $1,520 \mathrm{~cm}^{-1}[33,34]$. And XPS (Figure S5) indicates the formation of thin $\mathrm{Li}_{2} \mathrm{CO}_{3}(\sim 290 \mathrm{eV}$ in $\mathrm{C} 1 \mathrm{~s}, \sim 531 \mathrm{eV}$ in $\mathrm{O} 1 \mathrm{~s})$ layer that was removed after etching for $3 \mathrm{~nm}$ (Figure S5). Theformation of surface $\mathrm{Li}_{2} \mathrm{CO}_{3}$ (and maybe $\mathrm{LiOH}$ ) suggests that surface $\mathrm{H}_{2} \mathrm{O}$ and $\mathrm{CO}_{2}$ stabilize the potential energy of $\mathrm{Li}$ ions, and some of Li ions would be extracted from the LICGC to form $\mathrm{Li}_{2} \mathrm{CO}_{3}$ and $\mathrm{LiOH}$. This strong affinity of $\mathrm{Li}^{+}$to $\mathrm{H}_{2} \mathrm{O}$ and $\mathrm{CO}_{2}$, in other words, a low chemical potential of $\mathrm{Li}^{+}$, causes attractive force and accumulate $\mathrm{Li}$ ions at the region adjacent to the surface. 
On the second mechanism, the composition gradient, or segregation, may locally occur at surfacesand grain boundaries of LICGC. As mentioned above, LICGC consists of three phases, $\mathrm{Li}_{1+x}\left(\mathrm{Al}_{x} \mathrm{Ge}_{y} \mathrm{Ti}_{2-x-y}\right)\left(\mathrm{PO}_{4}\right)_{3}, \mathrm{Li}_{1+x+3 z} \mathrm{Al}{ }_{x}(\mathrm{Ge}, \mathrm{Ti})_{2-x}\left(\mathrm{Si}_{z} \mathrm{PO}_{4}\right)_{3}$ and $\mathrm{AlPO}_{4}$.In addition, recently, Safanama et al. studied phases involved on crystallization of $\mathrm{Li}_{1.5} \mathrm{Al}_{0.5} \mathrm{Ge}_{1.5}\left(\mathrm{PO}_{4}\right)_{3}$ (LAGP) from glass, and they revealed that glass-ceramic of LAGP exhibited phase separation consisting of an Al-rich phase and an Al-poor phase, which became homogeneous at higher temperature $[35,36]$. The composition change for $\mathrm{Al}$ at the surface of LICGC and the discrepancy of compositions obtained by XPS and ICP-OES may be explained by such phase segregation.However,the behavior of Li and Al cannot be explained. According to the structure and formula of NASICON-type materials, lithium and aluminum should show similar change in the composition, because substitution of $\mathrm{Ti}^{4+}$ and $\mathrm{Ge}^{4+}$ with $\mathrm{Al}^{3+}\left(\mathrm{Al}_{(\mathrm{Ti}, \mathrm{Ge})}\right)$ results in extra $\mathrm{Li}^{+}$at interstitial sites $\left(\mathrm{Li}_{i}{ }^{\circ}\right)$. Figure 5, however, shows an opposite trend.

Lastly, regarding the defects distribution on the surface of ionic crystals, which was studied by Kliewer, defects in ionic crystals may be accumulated or depleted depending on their relative charge and free energies of defect formation [16]. For example, when free energy of negative defects (i.e., $\left.\left.\mathrm{Al}_{(\mathrm{Ti}, \mathrm{Ge})}\right)^{\prime}\right)$ is larger than that of positive defects $\left(\mathrm{Li}_{i}{ }^{\circ}\right)$, Li increases at the surface while Al decreases. Apparently, such distribution agrees 
qualitatively with observed results. However, the defects concentration should converge toward bulk value with increasing the depth, while Alconcentration is apart from the bulk value and increases with increasing the depth.

At present moment, observed results have not been well explained with a single mechanism. Probably, some phenomena occur simultaneously, resulting in such the complicated change in the structure and the composition at the surface. Although the mechanism is still unclear, the phenomena observed in this work are not only interesting from the fundamental viewpoint, but also important on the application of solid electrolytes, such as ASSBs. In ASSBs, interfacial resistances between solid electrolytes and active materials as well as among solid electrolyte particles are critical problems. To overcome the interfacial resistance, it is important to reveal phenomena at the surface and interfaces of solid electrolyte. Actually, we have successfully suppressed the interfacial resistance among solid electrolyte particles without sintering by surface modification [17].

\section{Conclusion}

By three surface-sensitive analyses, GIXD, ATR-FTIR, and XPS, it was revealed that local structure and composition around the surface region of the LICGC changes 
depending on the depth. At the very surface, lattice was expanded, and with increasing the depth from the surface, lattice shrank sharply, and then expanded again gradually. The change in the lattice was accompanied by $\mathrm{Li}$ and $\mathrm{Al}$ composition. It is supposed that the change in the local structure and composition is caused by various mechanisms including mechanical/chemical change, segregation and defects distribution.

\section{Acknowledgements}

The authors would like to thank Mr. Hiroshi Furukawa for XPS operation. We are thankful to Prof. Stefan Adams for his helpful discussion. A financial support by Advanced Low Carbon Technology Research and Development Program of Japan Science and Technology Agency for Specially Promoted Research for Innovative Next Generation Batteries (JST-ALCA SPRING) is gratefully acknowledged.

\section{References}

[1]N. Ohta, K. Takada, L. Zhang, R. Ma, M. Osada, T. Sasaki, Adv. Mater. 18 (2006) 2226-2229.

[2]T. Kobayashi, Y.Imade, D.Shishihara, K. Homma, M. Nagao, R. Watanabe, T. Yokoi, 
A. Yamada, R.Kanno, T.Tatsumi, J. PowerSources, 182 (2008) 621-625.

[3]M. Kotobuki, H.Munakata, K.Kanamura, Y. Sato, T. Yoshida, J. Electrochem. Soc. 157 (2010) A1076-A1079.

[4] P. Knauth, Solid State Ionics 180 (2009) 911-916.

[5]G. Adachi, N.Imanaka, H.Aono, Adv. Mater. 8 (1996) 127-135.

[6]Y. Inaguma, L. Chen, M. Itoh, T. Nakamura, Solid State Commun. 86 (1993) 689-693.

[7]M. Tatsumisago, A. Hayashi, Solid State Ionics 225(2012) 342-345.

[8]N. Kamaya, K. Homma, Y.Yamakawa, M. Hirayama, R.Kanno, M.Yonemura, T.Kamiyama, Y. Kato, S. Hama, K. Kawamoto, A. Mitsui, Nature Mater. 10 (2011) $682-686$.

[9]A. Sakuda, A. Hayashi, M. Tatsumisago, Chem. Mater. 22 (2010) 949-956.

[10]M. Tatsumisago, R. Takano, K.Tadanaga, A. Hayashi, J. Power Sources 270(2014) 603-607.

[11]S. Ohta, S.Komagata, J. Seki, T. Saeki, S.Morishita, T.Asaoka, J. Power Sources238 (2013) 53-56.

[12]T. Okumura, T. Nakatsutsumi, T. Ina, Y. Orikasa, H. Arai, T. Fukutsuka, Y. Iriyama, T. Uruga, H. Tanida, Y. Uchimoto, Z. Ogumi, J. Mater. Chem. 21 (2011) 10051-10060. 
[13]H. Yamada, Y.Oga, I.Saruwatari, I. Moriguchi, J. Electrochem. Soc. 159 (2012) A380-A385.

[14]H. Yamada, K. Suzuki, K. Nishio, K. Takemoto, G.Isomichi, I.Moriguchi, Solid State Ionics 262 (2014) 879-882.

[15]K. Yamamoto, Y. Iriyama, T. Asaka, T. Hirayama, H. Fujita, C. A. J. Fisher, K. Nonaka, Y. Sugita, Z. Ogumi, Angew. Chem. Int. Ed., 49 (2010) 4414-4417.

[16]K. L. Kliewer, J. S. Köhler, Phys. Rev.140 (1965) A1226-A1240.

[17] H. Yamada, D. Tsunoe, S. Shiraishi, J. Phys. Chem. 119 (2015) 5412-5419.

[18] Y. Yamamoto, K. Yamamoto, J. Non-Crystal. Solids 356 (2010) 14-18.

[19] M. P. Seah, S. J. Spencer, A. G. Shard, J. Phys. Chem. B 117 (2013) 11885-11892.

[20]A. Delcorte, B. J. Garrison, K. Hamraoui, Anal. Chem. 81 (2009) 6676-6686.

[21] C. J. Brinker, G. W. Scherer, Sol-Gel Science, The Physics and Chemistry of Sol-Gel Processing, Academic Press, San Diego, 1990.

[22] P. Hoffmann, E. Knozinger, Surf. Sci. 188 (1987) 181-198.

[23] B. A. Morrow, A. J. McFarlan, J. Non-Cryst. Solids 120 (1990) 61-71.

[24] N. V. Kosova, E. T. Devyatkina, A. P. Stepanov, A. L. Buzlukov, Ionics 14 (2008)

303-311.

[25] C.M. Julien, P. Jozwiak, J. Garbarczyk, Proceedings of the International Workshop 
"Advanced Techniques for Energy Sources Investigation and Testing", Sofia, 2004, L4-1-12.

[26] K. Nakamoto, Infrared and Raman Spectra of Inorganic and Coodination Compounds, Part A, John Wiley \& Sons, Inc. New York, 1997, Sec. II.

[27] K. Nakamoto, Infrared and Raman Spectra of Inorganic and Coodination Compounds, Part B, John Wiley \& Sons, Inc.New York, 1997, Sec. III-12.

[28]A. Ait-Salaha, J. Doddb, A. Maugerc, R. Yazamib, F. Gendrona, C. M. Juliena,Z. Anorg. Allg. Chem.632 (2006) 1598-1605.

[29] Y. Yamamoto, Surf. Interface Anal. 44 (2012) 931-933.

[30] Y. Yamamoto, K. Yamamoto, Optic. Mater. 33 (2011) 1927-1930.

[31] F. Ding, W. Xua, Y. Shao, X. Chen, Z. Wang, F. Gao, X. Liu, J.-G. Zhang, J. Power Sources 214 (2012) 292-297.

[32] R. P. Awbery, D. A. Broughton, S.C. Tsang, J. Nuclear Mater. 373 (2008) 94-102.

[33] S. Barusseau, B. Beden, M. Broussely, F. Perton, J. Power Sources 54 (1995) 296-300.

[34] D. Aurbach, H. Gottlieb. Electrochim.Acta, 34 (1989) 141-156.

[35] D. Safanama, Z. F. Yow, H. Yan, D. H. Chua, S. Adams, Extended Abstract of the 20th International Conference on Solid State Ionics, C5.04, Keystone, USA (2015). 
[36] D. Safanama, P. R. Rayavarapu, H. Yan, D. S. Adams, Extended Abstract of the 8th International Conference on Materials for Advanced Technologies of the Materials Research Society of Singapore, A-PO167, Singapore (2015).

\section{Figure Captions}

Figure 1. GIXD profiles of LICGC obtained with various incidence angles obtained by the asymmetry mode. (a) Wide range and (b) around (113).

Figure 2.(a) $d$-value of (113) plane of LICGC as a function of attenuation depth. A horizontal grey band shows a $d$-value for bulk LICGC (3.588(1) $\AA$ ). Inset shows an enlarged plot for shallow range. (b) Deviation of $d$-values for (113) and (024) planes.

Figure 3.FT-IR spectra of LICGC. (a) Wide range and enlarged spectra for (b) 500-1,900 $\mathrm{cm}^{-1}$, (c) 700-1,500 $\mathrm{cm}^{-1}$ and (d) 1,200-2,000 $\mathrm{cm}^{-1}$. In each plot, ATR spectrum and transmission spectrum are shown at top and bottom, respectively.

Figure 4.XP spectra of LICGC for (a) P2p, Ge3p, and A12s, and (b) A12p, Ti3p and Li1s. The numbers on each spectrum show etched depth from the bare surface of LICGC, 
which is estimated from a standard $\mathrm{SiO}_{2}$ film. For spectra obtained after $147 \mathrm{~nm}$ etching, fitting curves are also shown with dotted lines (each peak and total) and narrow solid lines (background).

Figure 5. Depth profiles of elements of LICGC. Vertical axes shows a relative atomic ratio to phosphorus. Depth is estimated from a standard $\mathrm{SiO}_{2}$ film. Dashed lines shows bulk composition estimated from ICP-OES. 
Table 1. Additional peaks observed in ATR and transmission spectra related to $\mathrm{OH}$ and $\mathrm{C}=\mathrm{O}$ vibrations.

\begin{tabular}{llll}
\hline & Vobration mode & Bulk (transmission) & Surface (ATR) \\
\cline { 2 - 3 } & $v_{1}\left(A_{1}\right)$ & $950 \mathrm{~cm}^{-1}$ & $978 \mathrm{~cm}^{-1}$ \\
& & $1,028 \mathrm{~cm}^{-1}$ & $1,089 \mathrm{~cm}^{-1}$ \\
& & $1,116 \mathrm{~cm}^{-1}$ & $1,123 \mathrm{~cm}^{-1}$ \\
& $v_{4}\left(F_{2}\right)$ & $1,184 \mathrm{~cm}^{-1}$ & $1,184 \mathrm{~cm}^{-1}$ \\
& & $588 \mathrm{~cm}^{-1}$ & $603 \mathrm{~cm}^{-1}$ \\
& & $644 \mathrm{~cm}^{-1}$ & $644 \mathrm{~cm}^{-1}$ \\
\hline Lantern unit & & $665 \mathrm{~cm}^{-1}$ & $665 \mathrm{~cm}^{-1}$ \\
\hline & & $1,265 \mathrm{~cm}^{-1}$ & $1,265 \mathrm{~cm}^{-1}$ \\
\hline & & $717 \mathrm{~cm}^{-1}$ & $717 \mathrm{~cm}^{-1}$ \\
\hline
\end{tabular}



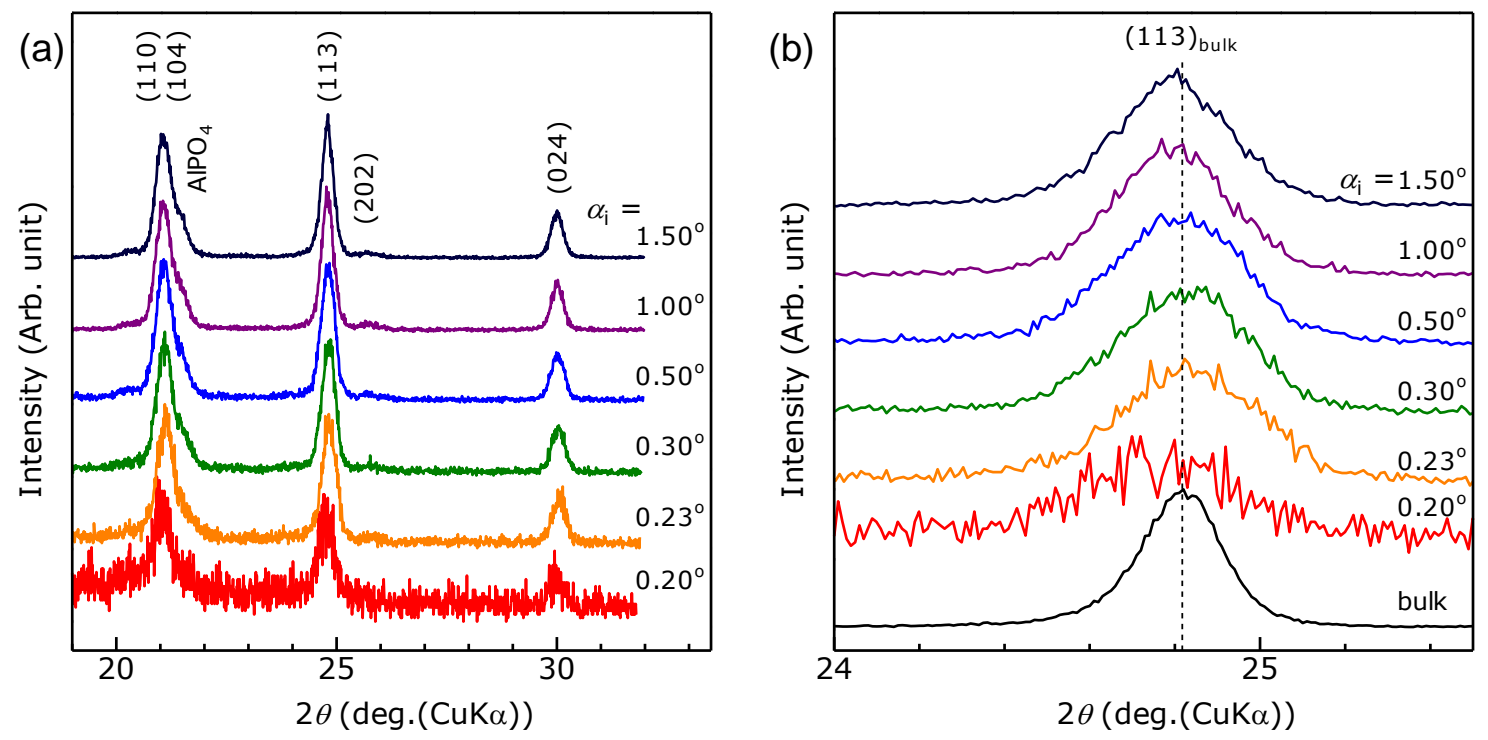

Figure 1. H. Yamada, et al. 

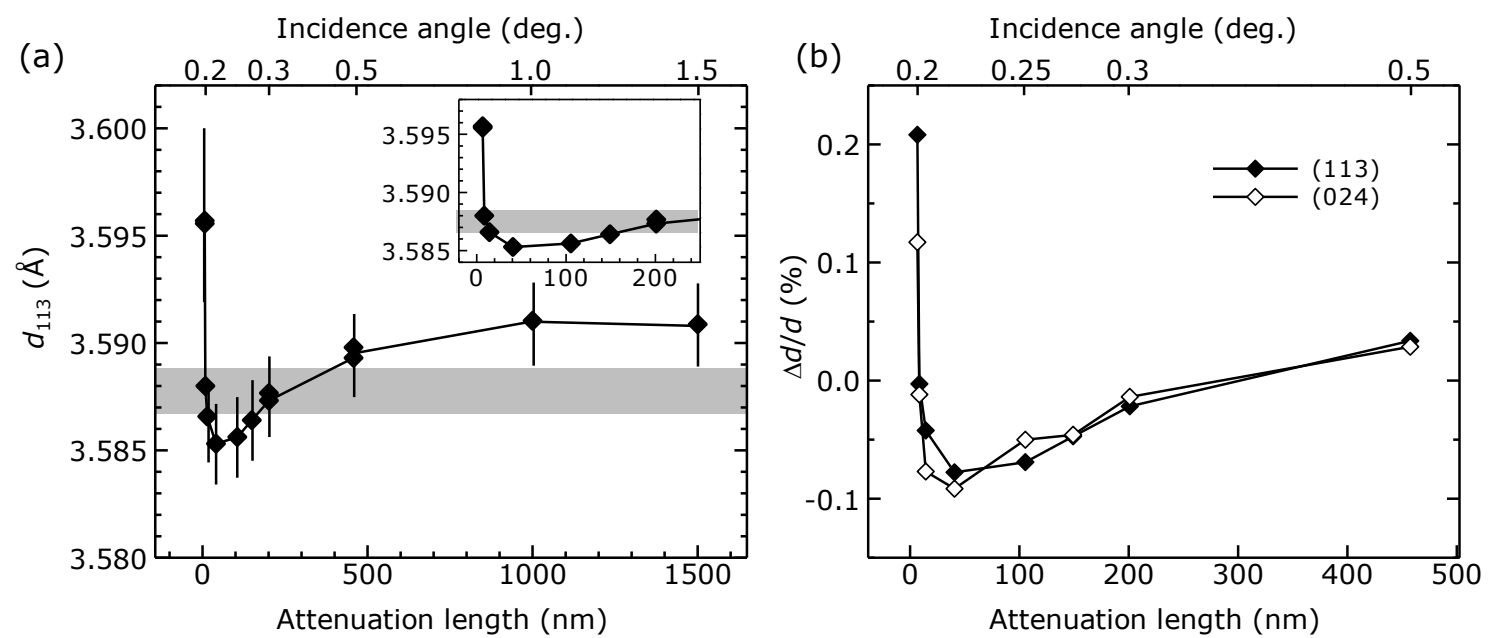

Figure 2. H. Yamada, et al. 

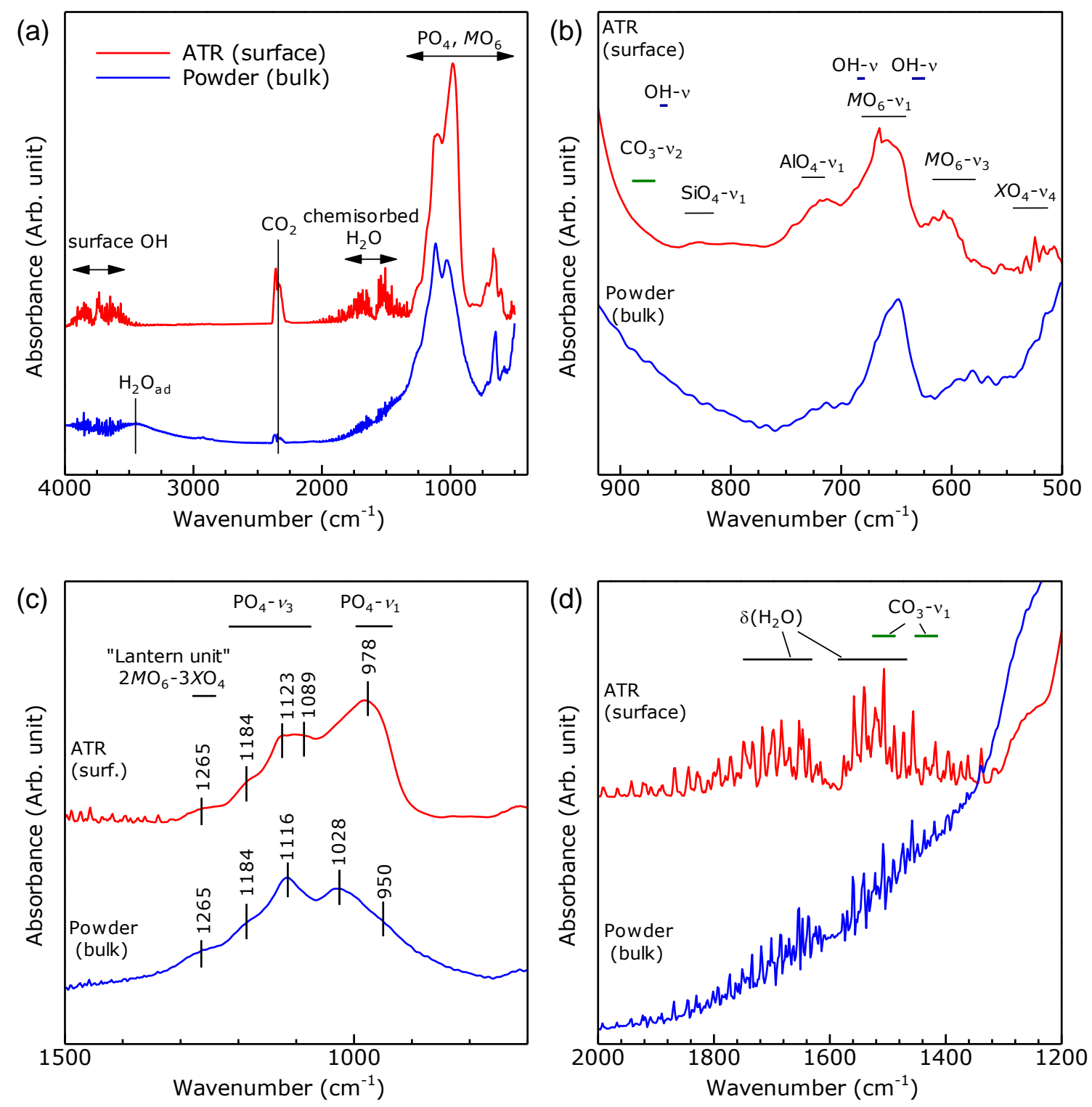

Figure 3. H. Yamada, et al. 

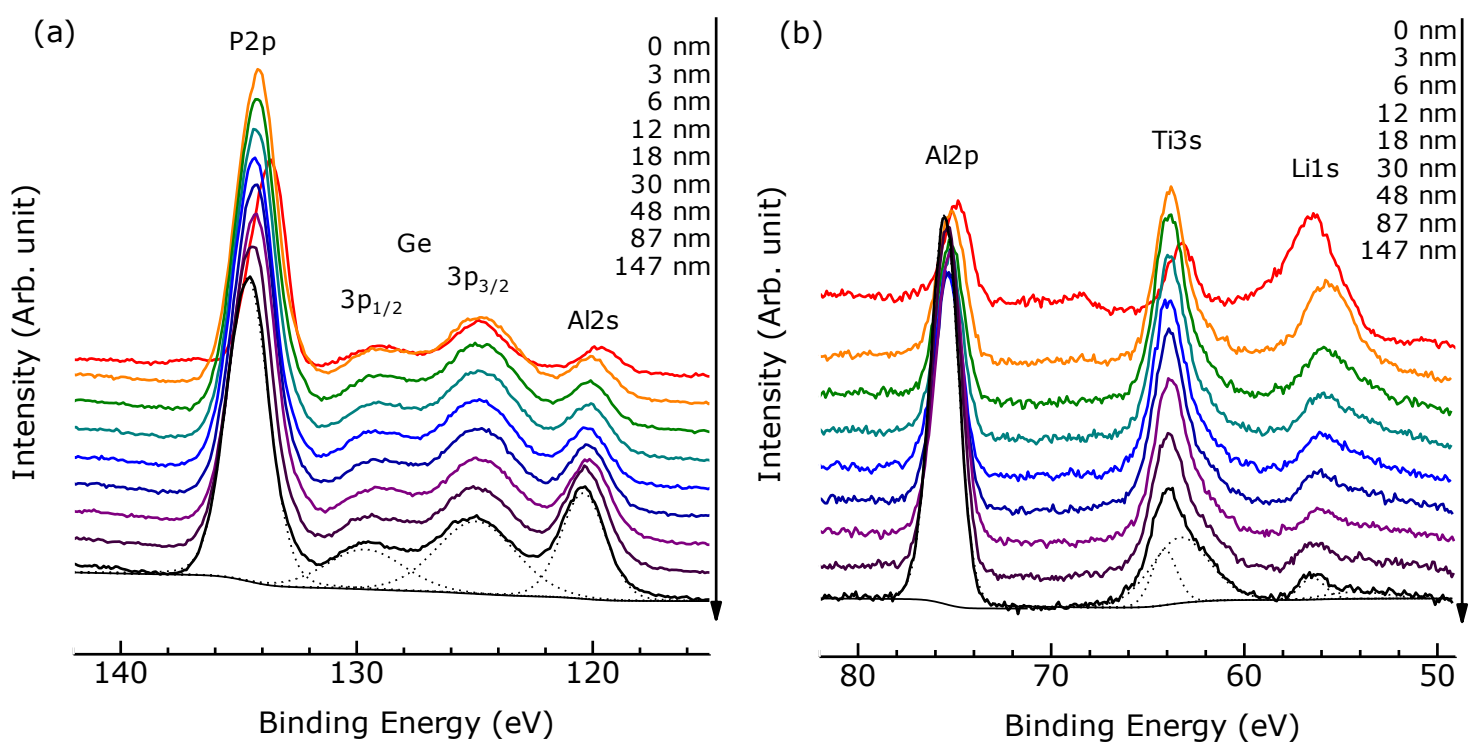

Figure 4. H. Yamada, et al. 


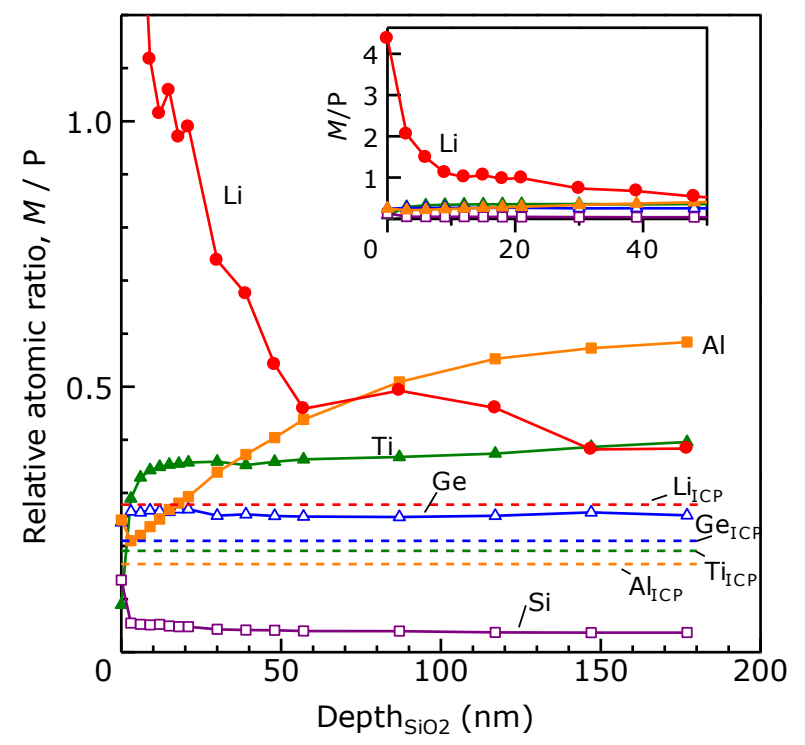

Figure 5. H. Yamada, et al. 